\section{Obesidade e pobreza: o aparente paradoxo. Um estudo com mulheres da Favela da Rocinha, Rio de Janeiro, Brasil}

\author{
Obesity and poverty: the apparent paradox. \\ A study among women from the Rocinha slum, \\ Rio de Janeiro, Brazil
}

Vanessa Alves Ferreira 1 Rosana Magalhães ${ }^{2}$

\section{Introdução}

In recent decades the Brazilian population has undergone intense changes in its nutritional conditions, especially with an increase in obesity. According to the National Survey on Health and Nutrition in 1989, 32.0\% of adults were overweight. However, distribution of the problem is not homogeneous. The highest prevalence occurs among poor women in the Southeast. Understanding this apparent paradox requires the search for approaches capable of overcoming simplistic interpretations about eating practices. Thus, the objective of this study was to understand obesity combined with poverty, focusing beyond economic determinants on constraints of a cultural and symbolic nature. From this perspective, the study analyzed the daily lives of poor women who used a Municipal Health Center and resided in the Rocinha slum in Rio de Janeiro. The results showed the complexity of the relationship between obesity and poverty. Cultural and material life aspects as well as different concepts of eating and the body proved to be fundamental elements for the analysis of the multiple facets of obesity in Brazil.

Poverty; Obesity; Nutritional Status; Food Habits
Importantes transformações demográficas, econômicas, sociais e tecnológicas ocorridas nas últimas décadas propiciaram mudanças significativas no padrão de morbi-mortalidade nas sociedades modernas. O aumento da expectativa de vida, a redução das mortes por doenças infectoparasitárias e o aumento da mortalidade por doenças crônicas não transmissíveis tornaram complexo o quadro de saúde das populações. Neste contexto, mudanças nos indicadores nutricionais também foram observadas, especialmente no que se refere ao incremento da obesidade. Informações da Organização Mundial da Saúde (OMS) 1 revelam que a obesidade já atinge $7,0 \%$ da população mundial e o sobrepeso cerca de 14,0 a $20,0 \%$. Tal magnitude tem levado alguns autores a caracterizá-la como uma problemática significativa em todo o mundo ${ }^{2}$. A obesidade assume relevância para o campo da saúde na medida em que está associada a um grande número de doenças incluindo: as patologias cardiovasculares e cerebrovasculares, os distúrbios metabólicos, diversos tipos de câncer, patologias do aparelho digestivo, entre outras. Somam-se aos danos fisiológicos impactos psicossociais relacionados à questão do estigma e da discriminação a indivíduos sob esta condição ${ }^{3}$. A obesidade revela-se, portanto, como um agravo extremamente complexo que se constitui num 
dos maiores desafios de saúde pública deste século.

No Brasil, o avanço do excesso de peso foi constatado mediante dados obtidos pela Pesquisa Nacional sobre Saúde e Nutrição (PNSN) 4. O agravo foi diagnosticado em 27 milhões de indivíduos, correspondendo a 32,0\% da população brasileira total. Destes, 6,8 milhões foram considerados obesos apresentando Índice de Massa Corporal (IMC) igual ou superior a $30 \mathrm{~kg} / \mathrm{m}^{2}$. No entanto, o perfil da obesidade apresenta comportamento pouco homogêneo: diferenças regionais e entre grupos populacionais são evidenciadas. A obesidade tende a ser mais freqüente em áreas de melhor desenvolvimento tais como o sul e o sudeste do país. Somente a Região Sul totaliza cerca de 5 milhões de adultos com excesso de peso. Mas, a situação é alarmante nos estados do Sudeste. Em termos absolutos é a região que apresentou a situação mais grave com aproximadamente 10 milhões de adultos com sobrepeso e cerca de 3 milhões e meio com obesidade 4 . A obesidade tende, ainda, a ser um fenômeno presente na zona urbana em detrimento da área rural em todas as regiões brasileiras. Diferenças na prevalência da obesidade entre os grupos sociais também são observadas. O impacto é notório na população adulta feminina, especialmente a inserida nos menores percentis de renda. Dos 6,8 milhões de obesos diagnosticados pela PNSN 4, $70,0 \%$ eram do sexo feminino. A população de baixa renda é a mais atingida, apresentando a prevalência superior a $30,0 \%$ do total de mulheres com excesso de peso. A proporção chega a ser drástica configurando-se hoje como o maior problema alimentar no Brasil 4.

Dentro desta perspectiva, o objetivo desse estudo foi investigar o fenômeno da obesidade no contexto da pobreza. Buscou-se compreender este aparente paradoxo com base na aproximação com abordagens mais amplas capazes de superar interpretações polarizadas nos aspectos biológicos ou sociais. O estudo procurou combinar aspectos epidemiológicos ligados ao quadro de crescimento da obesidade pela utilização de dados secundários 4,5,6 com informações de natureza sócio-cultural e simbólica. Para isso, o objetivo foi analisar as práticas alimentares de um grupo de mulheres usuárias do Centro Municipal de Saúde Píndaro de Carvalho Rodrigues (CMS da Gávea) e moradoras da Favela da Rocinha, localizada na zona sul metropolitana do Rio de Janeiro, Brasil. $O$ estudo teve a perspectiva de combinar dife- rentes possibilidades analíticas visando, porém, dar ressonância aos aspectos sócio-culturais e simbólicos. Dessa forma, privilegiou-se o discurso das mulheres a respeito de sua alimentação, seu corpo e suas condições de vida e trabalho.

\section{Obesidade: uma enfermidade multifatorial}

A obesidade é uma doença crônica definida como o acúmulo excessivo de tecido adiposo num nível que compromete a saúde dos indivíduos 1. Embora sua etiologia não esteja totalmente esclarecida, existe um certo consenso na literatura de que ela é causada pela interação de fatores genéticos, metabólicos, endócrinos, nutricionais, psicossociais e culturais que conferem a essa enfermidade uma natureza multifatorial 7. Operacionalmente, é diagnosticada pelo parâmetro estipulado pela OMS 1 - o IMC, obtido por intermédio do cálculo da relação entre peso corpóreo $[\mathrm{kg}]$ e estatura $\left[\mathrm{m}^{2}\right]$ dos indivíduos. Com tal parâmetro são considerados obesos os indivíduos cujo IMC encontra-se num valor igual ou superior a $30 \mathrm{~kg} / \mathrm{m}^{2}$.

Pode-se dizer que a obesidade é um atributo físico, percebido, interpretado e influenciado pelo sistema social. Valores sócio-culturais relacionados à obesidade podem, por conseguinte, variar de uma sociedade para outra, nos diferentes contextos históricos. Neste sentido, a corpulência que no passado esteve associada à idéia de saúde no imaginário coletivo hoje tem seu significado transformado 3,8. Segundo Baudrillard 9 (p. 139), nas sociedades modernas têm vigorado, atualmente, uma "nova ética em relação ao corpo: o culto narcisista, dietético, higiênico e terapêutico". O corpo desejado hoje é o funcional por vincular-se a símbolos de beleza, realização pessoal e erotismo. No entanto, padrões definidos para a obesidade assumem contornos distintos em cada sociedade e também entre diferentes grupos sociais. Em algumas sociedades a obesidade feminina tem sido caracterizada como símbolo de beleza e maternidade 8 . Mulheres jovens africanas desenvolvem a obesidade com o intuito de incrementar seus atributos físicos e melhorar suas relações conjugais 3 . A percepção da obesidade em homens e mulheres também pode ser distinta: como alguns estudiosos têm observado a obesidade pode estar associada às idéias de "sucesso econômico, força política e condição social” 8 (p. 355). Os líderes polí- 
ticos na tribo Novo Guinca são homens obesos. Em Bemba, África do Sul, o excesso de gordura nos homens representa além de sucesso econômico, força espiritual. Estereótipos são criados e recriados em torno das relações entre corpo, força e liderança.

De acordo com Mauss 10 (p. 217): “o corpo é o primeiro e o mais natural instrumento do homem" e, cada sociedade impõe ao homem uma expectativa em torno do corpo. Para Foucault 11, em qualquer sociedade o corpo é um lócus de poder. Neste sentido, os corpos podem ser submissos - "corpos dóceis" 11 (p. 117) - sujeitos a coerções e domínios ou também a experiências de confronto e resistência. Nesta direção, Boltanski 12 (p. 145) afirma que a preocupação que os sujeitos depositam sobre o corpo "cresce quando eles se elevam na hierarquia social". Para o autor, os cuidados estéticos tendem a predominar entre as classes sociais privilegiadas em que se verifica o maior consumo de produtos de tratamento para o corpo e a prática de um estilo de vida mais saudável. Essas ações podem ser explicadas pela relação mais reflexiva com o corpo por parte desses segmentos, em função do melhor nível educacional e intelectual. Além disso, para Sobal 3, a condição material do grupo permite a adesão a um estilo de vida saudável. À medida que tais segmentos normalmente assumem ocupações de prestígio e usufruem de maior autonomia, existiria, portanto, uma tendência maior à incorporação de tais comportamentos. Inversamente, nas classes populares a atenção prestada ao corpo pode ser menos freqüente. Particularmente neste grupo, o uso do corpo pode compreender uma visão mais utilitária, fruto da importância da força física nas ocupações desempenhadas 12 . Contudo, vale ressaltar que atualmente o corpo magro e atlético tem sido valorizado e imposto pela mídia e pela moda com impacto importante, sobretudo nas classes média e alta. Mas também atinge as classes populares em que se verifica a admiração por modelos e atrizes de televisão que apresentam esses estereótipos de corpo. Interessante notar que contrariamente existe por parte das camadas socialmente abastadas a veiculação do corpo "gordo" a pessoas que realizam funções mais modestas como as cozinheiras, revelando que os estereótipos estão presentes, demarcando muitas vezes a condição social.

A perspectiva da construção social do corpo tem servido de fundamento para diferentes trabalhos sócio-antropológicos 13,14,15. Nesses estudos as desigualdades no acesso aos alimentos podem conduzir os grupos menos favorecidos a diferentes arranjos de sobrevivência. As estratégias de consumo alimentar estariam, assim, caracterizadas pela seleção de gêneros baratos e de alta densidade calórica como as gorduras e os açúcares através dos quais os pobres conseguem as calorias de que necessitam para sobreviver. Fundamentalmente, tais condutas apresentam-se como recurso importante para combater a fome - ameaça permanente no cotidiano diário das classes populares 16.

Segundo Aguirré 15, condutas de subconsumo alimentar têm afetado particularmente as mulheres pobres como conseqüência da " $a u$ to-exclusão de comida em favor das crianças $e$ do marido" 15 (p. 13). Foi o que constatou a autora em estudo com mulheres pobres e obesas argentinas. O papel social assumido pelas mulheres enquanto donas de casa no controle e na distribuição da comida no lar favorecia a negligência do seu próprio consumo. Dessa forma, Aguirré observou que as mulheres obesas argentinas obtinham a sensação de plenitude e combatiam a fome através do consumo de pães e infusões açucaradas. Para a autora, este padrão de alimentação associado à desvalorização social do corpo sofrida por essas mulheres tem contribuído para a prevalência de obesidade no grupo. Para maior aprofundamento sobre esta questão ver Gross 17. Nesta mesma direção, os trabalhos de Silva 18 e Tonial 19 com mulheres obesas de baixa renda no Brasil revelaram um padrão de consumo alimentar insuficiente sob o ponto de vista nutricional. Segundo as autoras, as precárias condições de vida dessas mulheres impunham a seleção de itens altamente calóricos e de baixo valor nutritivo.

\section{Universo do estudo: - Centro Municipal de Saúde da Gávea e a Favela da Rocinha}

O CMS da Gávea localiza-se na zona sul do Município do Rio de Janeiro e possui uma população adstrita de cerca de 210 mil habitantes. Abrange os bairros de Ipanema, Lagoa, Jardim Botânico, Gávea e São Conrado. E as comunidades da Rocinha, do Vidigal, Vila Canoas, Parque da Vila da Cidade, Chácara do Céu e Horto. As mulheres investigadas eram usuárias do CMS da Gávea e moradoras da Favela da Rocinha. A Rocinha situa-se no morro Dois Irmãos e foi outorgada bairro no ano de 1993. Apresenta uma enorme diversidade sócio-econômica, demográfica e cultural, sendo considerada a maior favela da América Latina. Os dados acerca de seu contingente populacional, ainda que controversos, revelam a permanente expansão da favela. A associação de moradores 
do bairro afirma que a população atualmente é composta por 200 mil habitantes com taxas anuais de crescimento de 3,07\%. O perfil sóciodemográfico da Rocinha revela que sua população é predominantemente de adultos jovens com um contingente maior de indivíduos do sexo feminino. No que se refere à renda, constatou-se uma faixa de rendimentos entre um e cinco salários mínimos mensais. O perfil dos moradores revela, ainda, que a maior parte é imigrante, oriunda de estados da Região Nordeste do país 20 .

\section{Histórias de vida, histórias de luta: metodologia e o universo social da pesquisa}

Este estudo buscou uma aproximação com o vocabulário sobre a alimentação, o corpo, a vida, o trabalho e a obesidade das mulheres da Rocinha por intermédio de instrumental qualitativo. A pesquisa qualitativa assume como tarefa central o entendimento da realidade humana vivida socialmente 21 . Neste tipo de metodologia a preocupação central não é a quantificação, mas a compreensão intrínseca de seu objeto de análise em que é priorizado um amplo universo de valores, percepções, hábitos e atitudes dos sujeitos 22 .

O trabalho de campo totalizou 12 entrevistas. Os critérios para a seleção do grupo incluíram: o diagnóstico da obesidade com base no parâmetro do IMC e a caracterização da condição de vulnerabilidade social pelo levantamento de informações sobre condições de vida e pobreza. Neste último critério, fizemos uso de uma cesta de indicadores tal com propõe a literatura 23,24. Esta incluiu dados sobre renda, nível educacional, situação do domicílio, estrutura familiar, acesso a bens e serviços, condições de trabalho e lazer, entre outras informações. O instrumento para a coleta de dados seguiu um roteiro previamente estabelecido compreendendo quatro eixos investigativos. $\mathrm{O}$ primeiro constou de informações acerca da rotina alimentar das entrevistadas incluindo a aquisição dos gêneros, preparo, consumo, preferências e aversões alimentares. No segundo eixo, foram obtidos dados sobre a rotina diária de atividade física: meios de locomoção, tipo de atividade ocupacional, realização de atividade esportiva de lazer e horas assistindo à televisão. O terceiro eixo investigativo resgatou informações sobre a trajetória de vida das mulheres. Por último, foram obtidos dados sobre as percepções das mulheres quanto ao seu corpo, alimentação, condições de vida e trabalho.
Oportuno destacar que nesta investigação foram cumpridos os princípios éticos contidos na Declaração de Helsinki.

Dentre as 12 mulheres entrevistadas, sete apresentaram obesidade classe I e cinco obesidade classe II com riscos de co-morbidade moderado e grave, respectivamente 1 . No que diz respeito à faixa etária do nosso universo de pesquisa as mulheres apresentaram idades que variaram entre 34 a 60 anos. Na análise dos indicadores, combinaram-se dados, o que teve por objetivo discriminar mulheres submetidas a condições de vulnerabilidade social. Neste sentido, observou-se que no que se refere à cor, as mulheres entrevistadas eram em sua maioria pretas ou pardas. Esta característica está intimamente relacionada à pobreza no Brasil 25 . A baixa escolaridade também é uma característica dos pobres no país 25 . Neste aspecto, as mulheres da Rocinha apresentaram baixo nível educacional: menos de três anos de estudo. O perfil relaciona-se também a menores oportunidades de conquistar postos de trabalho de maior qualificação e melhor condição salarial. Assim, as mulheres se encontravam inseridas em ocupações de trabalho de menor prestígio exercendo atividades de diarista, doméstica, costureira, manicure, artesã, entre outras. Verificou-se que a vulnerabilidade à pobreza era agravada pela falta de uma rede de proteção social. As mulheres não apresentavam vínculos trabalhistas, desempenhando suas atividades sem carteira assinada. Além disso, o grupo não participava de nenhum tipo de programa governamental. A adesão a projetos como cheque-cidadão, bolsa alimentação e vale-refeição não foi verificada. A desqualificação das ocupações exercidas por essas mulheres se reflete em baixos rendimentos: a média salarial encontrada foi de um a dois salários mínimos mensais. Quanto aos arranjos familiares, podemos caracterizá-los como múltiplos, e a maior parte das informantes foi considerada chefe do domicílio. De acordo com Rocha 25 (p. 41): "famílias chefiadas por mulheres são mais vulneráveis à pobreza", no Brasil.

Na obtenção de informações acerca da trajetória de vida das mulheres foi possível verificar que a maioria das entrevistadas era imigrante, proveniente do Nordeste do país. Essas mulheres revelaram ter vivenciado um passado sofrido, de luta pela sobrevivência em meio à miséria e ao árduo trabalho do roçado. De acordo com elas, era do roçado que provinha a alimentação de toda a família. Na roça, plantavam a "mandioca", о "milho", о "feijão", o "inhame", a "abóbora”, a "batata”, gêneros comumente empregados em solos como os do Nordeste se- 
mi-árido. E deles obtinham uma variedade de preparações tais como: a "farinha", a "tapioca", o "beiju” e a "pamonha". Também realizavam pequenas criações de "fundo de quintal", especialmente a criação da "galinha" e do "porco".

A árdua vida na terra natal é transformada em um cotidiano igualmente difícil com a vinda para o Rio de Janeiro. As mulheres realizavam dupla jornada de trabalho que incluía os afazeres domésticos, os cuidados com os filhos e as ocupações do trabalho informal. E, ainda, a rotina de subir e descer as ladeiras da favela, as tensões desencadeadas pela falta de recursos, pelo convívio com a criminalidade e a violência urbana. Esta realidade foi expressa freqüentemente em declarações do tipo: "é muita luta!". Nos relatos das mulheres da Favela da Rocinha, raramente foram citados momentos de descanso e lazer. O hábito de assistir à televisão não se fez presente na rotina dessas mulheres: "não dá tempo nem de ver televisão. Com três filhos, se eu parar pra ver televisão as coisas acumulam"; "eu quase não vejo televisão". As atividades físicas de lazer demonstraram ser raras. Somente duas entrevistadas revelaram o hábito de fazer "caminhadas" com alguma regularidade.

\section{Percepções acerca da alimentação e do corpo obeso}

A rotina de alimentação das mulheres pobres e obesas da Rocinha foi analisada dentro da perspectiva qualitativa objetivando colher informações acerca dos critérios para a seleção dos alimentos. Neste sentido, verificou-se que a aquisição e o preparo dos gêneros são atividades realizadas pelas próprias mulheres. São elas que gerenciam a alimentação da família. A compra dos alimentos é feita em hipermercados localizados em bairros adjacentes à Rocinha ou na própria favela. O pagamento da alimentação adquirida é feito à vista, sempre em dinheiro revelando a exclusão do grupo da dinâmica do mercado de crédito.

Dentro dos critérios para o consumo alimentar no grupo, constatou-se a estreita relação existente entre alimentação e condições sócio-econômicas. O critério de seleção dos alimentos pelas mulheres da Rocinha é pautado, muitas vezes, pelo valor monetário dos gêneros. O preço dos itens define em algumas situações a seleção dos alimentos: "eu vou pelo preço"; "o que tiver mais barato eu compro". Condições adversas de vida fazem da aquisição dos alimentos uma prática extremamente penosa para o grupo: “às vezes, falta e não tem co- mo comprar"; "sempre falta alguma coisa". Para as mulheres é a pobreza que justifica a alimentação que conseguem realizar "pobre tem que comer o que o dinheiro dá"; "tem que comer o que tem". O regime alimentar das entrevistadas revelou ser monótono, com poucas variações do cardápio, composto basicamente por três refeições diárias: café da manhã, almoço e jantar. No entanto, a centralidade do regime recai sobre a refeição do almoço. As demais refeições nem sempre são habituais. $O$ almoço compreende o trinômio "arroz, feijão e carne", sendo a carne impreterivelmente o frango. $\mathrm{O}$ frango assume lugar de destaque no grupo, particularmente o frango assado. Não foi constatado o consumo de peixe e carne bovina pelas entrevistadas. Freqüentemente revelaram adicionar a "farinha" e o "macarrão" à alimentação do almoço. O consumo de legumes poucas vezes foi citado pelas entrevistadas, com exceção da "batata" e da "abóbora". Também não foi verificado o consumo de verduras e frutas na rotina alimentar das mulheres: "legumes eu não ligo muito"; "às vezes eu como uma fruta, mas é raro"; "verdura é muito difícil". A exclusão desses gêneros na dieta das mulheres relaciona-se, quase sempre, ao alto custo dos itens. Dessa forma, revelam o desejo em adquirir esses alimentos: "a gente tem vontade de comer, mas não pode; o dinheiro não dá"; "a gente vê essas coisas e não pode comprar". Os alimentos do almoço parecem revelar uma maior aproximação com a cultura alimentar nordestina na predileção por itens como os grãos, os tubérculos e os farináceos, conforme as mulheres se referiram quando falaram de sua alimentação na terra natal.

Informações sobre preferências no consumo de alimentos revelaram o lugar privilegiado para os doces, sobretudo, o "doce de banana", o "bolo de milho" e a "goiabada". O uso do açúcar no cotidiano do grupo mostrou-se freqüente, normalmente combinado ao café. Embora houvesse certo constrangimento em revelar seu consumo: "quase não como"; "é muito pouco". Esse comportamento também foi verificado nos relatos sobre o consumo de frituras, muitas vezes mediante frases ambíguas: “eu não devo, mas como”. Todavia, o gosto pelas preparações fritas foi freqüente entre as mulheres: "batata-frita", "polenta", "frango frito" e "carne de porco frita" foram os alimentos mais citados. Tais relatos denunciaram o conhecimento das relações entre a ingestão de açúcares e gorduras e a freqüência da obesidade. Outros itens apontados como alimentos preferidos foram as carnes mais ricas em gordura como a "carne de porco", a "feijoada" e a "carne seca". 
A alimentação idealizada pelo grupo incluía as "frutas", o "queijo", o "iogurte", o "peixe" e a "carne vermelha". Gêneros mais caros cujo acesso é difícil. A reduzida margem para a escolha da alimentação da família impõe o consumo de alimentos de digestão mais demorada que promovem maior saciedade. O regime "básico" refere-se à combinação "feijão e arroz" que representa "a comida que a gente precisa"; que "alimenta a gente"; que "enche a barriga" pela qual "não se passa fome". Entretanto, a desigualdade no acesso à alimentação adequada não parece ser o único motivo para a seleção desses itens no cotidiano das mulheres. Frente à diversidade de alimentos, os critérios de seleção dos itens parecem se aproximar do padrão de consumo alimentar do roçado. Dessa forma, a memória alimentar se revela no universo de alimentação das mulheres da Rocinha: "eu fui criada na roça comendo isso" e "eu fui acostumada assim" foram as principais justificativas relacionadas à seleção desses alimentos pelas entrevistadas. A manutenção de um padrão alimentar muito próximo do realizado na terra natal com a centralidade no arroz e feijão, na farinha e nos legumes cultivados no semi-árido tais como a batata e a abóbora nos leva a acreditar na presença de aspectos culturais interferindo na seleção da alimentação cotidiana do grupo.

$\mathrm{O}$ alimento para as mulheres pobres e obesas da Rocinha está associado à idéia de sobrevivência e manutenção da vida humana: "é $t u$ do que a pessoa necessita pra viver". A comida, por sua vez, assume um sentido ambíguo. Pode estar relacionada à comida classificada como "normal" ou ao "básico", referindo-se ao "arroz e feijão". Mas também pode relacionar-se ao excesso, a "gulodice". Contudo, é a comida “normal” que compõe a refeição. Refeição para as mulheres é o "almoço" em que aparece a comida que sustenta e satisfaz.

Valores acerca dos alimentos processados incluindo os enlatados assumem para as mulheres da Rocinha conotação negativa e são caracterizados como prejudiciais à saúde. Considerados alimentos "não naturais" relacionamse ao emprego de substâncias desconhecidas pelas mulheres que vivenciaram as experiências de plantar, colher e processar seus próprios alimentos no roçado. A comida da roça " $n a ̃ o t i-$ nha remédio", era "tudo natural, tudo fresco". Dessa maneira, os gêneros enlatados são rejeitados pelas mulheres: "enlatado eu acho horrível"; "eu não gosto muito de enlatado (...) eu acho que não faz bem". Assim como, alguns alimentos industrializados: "essas coisas industrializadas eu não compro, você não sabe onde foi feito"; "refrigerante eu não gosto porque eu acho que não faz bem". Contrariamente, o alimento "diet", embora industrializado, é relacionado pelas mulheres à saúde, o que revela ambigüidades e contradições no entendimento desses alimentos. Dessa forma, ele representa o alimento isento de açúcar e gordura, alimento "leve" utilizado "pra emagrecer". Por essa razão é desejado pelo grupo: "eu gosto"; “deve ser bom”. Apesar das mulheres não terem como adquirir - "só não dá pra comprar"; "é bem mais caro e eu nunca compro" - observamos a penetração das informações de profissionais de saúde e dos meios de comunicação entre o grupo.

\section{O corpo vivido, o corpo percebido}

As percepções do corpo revelaram que o excesso de peso se relaciona essencialmente ao aparecimento de sintomas clínicos diversos e a menor agilidade e disposição para o trabalho aparecendo em expressões como: "eu me sinto cansada"; "sinto falta de ar"; "dores nas pernas"; "problemas na coluna". Algumas mulheres relacionam as transformações do corpo a dois eventos de vida - o casamento e a gravidez: "foi depois de casar"; "eu acho que foi depois da gravidez do meu filho”. Porém, em geral, as alterações nas formas do corpo com o aumento do peso são percebidas por intermédio dos profissionais de saúde em consultas de rotina: "eu vim tratar da pressão aí a doutora achou que eu estava acima do peso e me mandou pra nutrição"; "eu vim à clínica geral e a doutora falou: você tem que perder peso, a senhora está muito acima do peso (...) eu vou mandar você pra nutrição". Notadamente, as mulheres da Rocinha não se percebem enquanto obesas; aqui parece vigorar uma imagem corporal distinta da verificada em outros grupos sociais. A obesidade para as mulheres investigadas pouco se relaciona a atributos estéticos. Notamos que a construção do corpo obeso se apresenta ambivalente no grupo. Assim, o corpo magro assume certa ambigüidade. Em oposição ao corpo gordo, o corpo magro é mais ágil: "você magra faz as coisas rápido, gorda não, cansa”. No entanto, se ficar magra é ter maior disposição, pode também significar a privação de alimentos e até a doença: "perder peso é ficar magra, é ficar doente, sem comida”. Logo, a valorização do corpo obeso está implícita no grupo. Se o corpo magro associa-se à privação de alimentos, à fraqueza e à doença; contrariamente o corpo obeso passaria a estar vinculado às noções de suficiência alimentar, força e saúde. Entretanto, constata-se que tal concepção é relativiza- 
da, ou seja, ao mesmo tempo em que o corpo obeso é desejado por estar ligado ao vigor e à saúde, também é julgado como "pesado" e, portanto, menos ágil. Nesse aspecto, o corpo magro passa a ser valorizado. Contudo, entre um corpo "magro ágil" e "magro doente" o último parece ser o mais ameaçador, já que para as classes populares a doença é o maior impedimento para a realização do trabalho 14. Tais concepções demonstram a relação do corpo com o trabalho e enfatizam a noção do corpo utilitário, apto à execução do trabalho 12 .

A perda de peso torna-se muito mais uma exigência dos profissionais de saúde do que propriamente uma demanda forte das mulheres: "eu preciso emagrecer, isso todos os médicos falam. O cardiologista fala, a médica ginecologista fala, todos falam, então só pode ser pra eu emagrecer". Ao mesmo tempo a conciliação entre as recomendações médicas e o cotidiano é difícil e, muitas vezes, acaba gerando sentimentos de culpa: "se eu fizer uma dieta legal, procurar fazer as coisas direitinho eu perco peso"; "eu tenho que levar mais a sério". Segundo Fischler 26, para a sociedade de consumo, os gordos são percebidos como os únicos responsáveis por sua condição. São gordos "porque comem muito e são incapazes de se controlar". Implicitamente são julgados como transgressores das normas. Mas, pouco a pouco, as mulheres revelaram os dilemas ligados à superação da obesidade: "com a comida que tenho em casa, eu não consigo"; "se eu tivesse uma dieta balanceada"; "um salariozinho melhor pra eu comprar mais coisa que ajudasse".

O papel do alimento enquanto elemento de conforto para a superação dos dilemas diários, das tensões ocasionadas pela falta de recursos, pela violência, pela responsabilidade com a casa e os filhos também surge na fala das mulheres: "quando eu tô tristinha eu vou lá e como"; "pra mim é nervoso, é ficar sozinha dentro de casa"; "eu acho que é muita responsabilidade, agora eu tenho que cuidar de dois filhos". Orbach 27 se refere a um sintoma singular que, segundo a autora, ocorre em muitos indivíduos com problemas de excesso de peso: a "fome emocional" 27 (p. 47). Diferentemente da necessidade de saciar a sensação física ocasionada pela falta do alimento, a "fome emocional" diz respeito à utilização da comida para apaziguar inquietações emocionais. Orbach 27 alerta, ainda, que muitas vezes a própria sensação de fome amedronta determinados indivíduos. Especialmente aqueles que tiveram experiências indesejáveis no passado como, por exemplo, quando não dispunham de comida suficiente na infância. Por essa razão, muitas pessoas comem antes que possam sentir fome.

\section{Obesidade - uma face da desigualdade social}

Na tentativa de desvendar o "paradoxo" da obesidade na pobreza, optou-se por privilegiar as múltiplas dimensões do fenômeno a fim de realizar um exame mais consistente sobre o tema. Nesse sentido, procurou-se sobrepor modelos explicativos reducionistas centralizados em apenas um aspecto do agravo, assim como, exames polarizados entre os aspectos biológico e social. Dessa forma, foram incorporados nesta investigação diferentes instrumentos analíticos que incluíram estudos epidemiológicos e trabalhos provenientes do campo das ciências econômicas e sociais. Esta conduta possibilitou uma melhor aproximação com o tema da obesidade na pobreza, permitindo reconhecer a ampla rede que envolve a prevalência do agravo no grupo feminino de baixa renda no Brasil.

Nesta perspectiva, foi possível constatar que a freqüência da obesidade entre as mulheres pobres no Sudeste do Brasil expressa na realidade os novos contornos da pobreza urbana e da exclusão social no país. O fenômeno da "metropolização da pobreza" 28, observado no país nos últimos anos, promoveu a concentração de pobres rurais no contexto das metrópoles urbanas, sobretudo, às do Sudeste. E no Rio de Janeiro, em particular, esta dinâmica se mostrou mais sensível 28. Essa nova conformação demográfica e social acabou por produzir intensas desigualdades no acesso a bens e serviços em determinados grupos sociais com notável impacto na população feminina. Neste aspecto, as mulheres têm sofrido transformações importantes no contexto do trabalho, da vida social e familiar. O que tem acarretado na pauperização das condições de vida do grupo. Atualmente, as mulheres estão mais sujeitas à vulnerabilidade social no país. Não raro, estão inseridas em postos de trabalho de menor prestígio e remuneração, submetidas a longas jornadas de trabalho, muitas vezes, sem vínculos trabalhistas e são, ainda, as mais atingidas pelo infortúnio do desemprego 29. Verifica-se também que as mulheres vêm ao longo das últimas décadas assumindo a chefia dos lares e o cuidado dos filhos, o que torna esses domicílios mais vulneráveis à pobreza 25.

Nesta direção, foram utilizados nesta investigação recursos analíticos que procuram articular os agravos de saúde às condições de vida dos sujeitos que, de certo, possibilitaram uma melhor compreensão deste fenômeno aparentemente paradoxal. Entendendo a obesidade enquanto uma enfermidade não apenas física, mas social, derivada das interações vividas no 
cotidiano dos sujeitos, constatou-se que o fenômeno da obesidade na pobreza nada tem de contraditório. Na realidade, a obesidade está articulada à dinâmica social e adquire contornos próprios em cada segmento. A pluralidade de circunstâncias vividas pelas mulheres da Rocinha revelou a combinação de elementos materiais, culturais e simbólicos que operam na freqüência da obesidade no grupo. O cotidiano de vida das mulheres da Favela da Rocinha tende a moldar os hábitos de alimentação e de atividade física, expresso num perfil de corpo obeso. A obesidade apresenta, por conseguinte, múltiplos determinantes. Ela não parece ser resultado tão somente de estratégias de consumo alimentar impostas pela desigualdade no acesso à nutrição suficiente, mas também é modelada por concepções simbólicas próprias deste grupo social. O corpo obeso é, dessa forma, cúmplice da história de vida das mulheres da Rocinha. É por intermédio dele que o grupo preserva sua identidade, mantém costumes e crenças culturais e encontra refúgio para os inúmeros dilemas impostos pela vida em meio à pobreza e à escassez. Neste sentido, singularidades e especificidades ligadas ao cotidiano das mulheres, bem como hábitos e costumes nordestinos moldam as escolhas alimentares e o perfil de atividade física do grupo. Logo, obesidade e pobreza se entrelaçam numa dinâmica própria, multifacetada. Longe de se tratar de um paradoxo, a pobreza parece de fato explicar a obesidade entre as mulheres da Rocinha. Sob tal aspecto torna-se importante salientar a necessidade de desconstruir a idéia da obesidade enquanto uma enfermidade associada à abundância e aos excessos alimentares. Na verdade, a obesidade surge como mais uma face da desigualdade social no país. As abordagens que vinculam a obesidade às situações de abundância e riqueza perdem seu

\section{Resumo}

Nas últimas décadas, a população brasileira experimentou intensas transformações em suas condições de nutrição, especialmente com o incremento da obesidade. De acordo com a Pesquisa Nacional sobre Saúde e Nutrição, realizada em 1989, 32,0\% dos adultos apresentaram excesso de peso. No entanto, a distribuição do problema não é homogênea. A maior prevalência ocorre em mulheres pobres da Região Sudeste do país. A compreensão desse aparente paradoxo impõe a busca de abordagens capazes de superar interpretações simplistas sobre as práticas alimentares. Assim, o objetivo desse estudo é compreender a obesidade combinada à pobreza, focalizando além dos determinantes alcance explicativo no caso da população pobre feminina no Brasil.

\section{Conclusão}

Os resultados encontrados nesta pesquisa apontam para a apreensão da obesidade como uma face da pobreza urbana no país. Diante disso, torna-se importante sinalizar a necessidade de se reconhecer os novos contornos da pobreza, assim como, o mosaico de situações cotidianas vivenciadas pelos grupos socialmente vulneráveis, para o melhor enfrentamento da obesidade. O conhecimento acerca da realidade vivida pelos grupos populacionais no Brasil mostrase especialmente importante para que estratégias em saúde pública sejam traçadas. Reconhecendo que os componentes da vida social dos indivíduos contribuem para a qualidade de vida e bem estar, o levantamento de informações sobre o cotidiano desses grupos possibilita o melhor enfrentamento dos agravos de saúde, sobretudo, da obesidade ${ }^{30}$. Nesta direção, as ações de promoção à saúde, a perspectiva de territorialização das intervenções públicas e a articulação de ações educativas, de geração de renda e de inserção social, podem ter maior impacto no equacionamento da obesidade em mulheres pobres no país. Por fim, este trabalho aponta um resgate da abordagem multidimensional para o estudo dos agravos nutricionais no país. Os exames que propõem a articulação das dimensões do corpo, do trabalho, da cultura, da condição de classe e saúde devem ser incorporados às temáticas atuais. A compreensão do fenômeno da obesidade na pobreza obriga, portanto, superar quadros conceituais restritos e a construção de novas agendas de investigação. Dessa forma, espera-se que este trabalho possa contribuir para novos debates e desdobramentos sobre o tema da obesidade no Brasil. econômicos, constrangimentos de natureza cultural e simbólica. Nesta perspectiva, o estudo analisou o cotidiano de vida de mulheres pobres e obesas, usuárias de um Centro Municipal de Saúde e moradoras da Favela da Rocinha, Rio de Janeiro. Os resultados revelaram a complexidade da relação entre obesidade e pobreza. Os aspectos culturais e materiais de vida, assim como as diferentes concepções de alimentação e de corpo demonstraram ser elementos fundamentais para a análise das múltiplas faces da obesidade no Brasil.

Pobreza; Obesidade; Estado Nutricional; Hábitos Alimentares 


\section{Colaboradores}

V. A. Ferreira foi responsável pela elaboração, redação e revisão do artigo. R. Magalhães participou da orientação da pesquisa, elaboração e revisão do artigo.

\section{Referências}

1. World Health Organization. Obesity: preventing and managing the global epidemic. Geneva: World Health Organization; 1997. (Report of a WHO Consultation on Obesity).

2. Popkhis BM, Doak C. The obesity epidemic is a worldwide phenomenon. Nutr Rev 1998; 56:106-14.

3. Sobal J. Obesity and socioeconomic status - a framework for examining relationship between physical and social variables. Med Anthropol 1991; 13:231-47.

4. Ministério da Saúde. Pesquisa Nacional de Saúde e Nutrição. Brasília: Instituto Nacional de Alimentação e Nutrição; 1989.

5. Pena M, Bacallo J, organizadores. La obesidad en la pobreza - un nuevo reto para la salud publica. Washington DC: Organización Panamericana de la Salud; 2000.

6. Coitinho DO, Leão MM, Recine E, Sichieri R. Condições nutricionais da população brasileira: adultos e idosos. Brasília: Ministério da Saúde/ Instituto Nacional de Alimentação e Nutrição; 1991.

7. Mondini L, Monteiro CA. Relevância epidemiológica da desnutrição e da obesidade em distintas classes sociais: métodos de estudo e aplicação à população brasileira. Rev Bras Epidemiol 1998; 1:28-39.

8. Brown PJ, Konner M. An anthropological perspective on obesity. In: Goodman AH, Dufour GH, editors. Nutritional anthropology - biocultural perspectives on food and nutrition. Mountain View: Mayfield Publishing Company; 1999. p. 347-58.

9. Baudrillard J. A sociedade de consumo. Rio de Janeiro: Elfos Editora/Lisboa: Edições 70; 1995.

10. Mauss M. Sociologia e antropologia. São Paulo: EPU; 1974.

11. Foucault M. Vigiar e punir: nascimento da prisão. Petrópolis: Editora Vozes; 1997.

12. Boltanski L. As classes sociais e o corpo. Rio de Janeiro: Graal; 1979.

13. Velho OG, organizador. Projeto hábitos alimentares em camadas de baixa renda. Rio de Janeiro: Museu Nacional, Universidade Federal do Rio de Janeiro; 1977. (Relatório do Grupo de Pesquisa do Museu Nacional).

14. Woortmann KA. A comida, a família e a construção do gênero feminino. Dados Rev Ciênc Sociais 1986; 29:103-29.

15. Aguirré P. Aspectos socioantropológicos de la obesidad en la pobreza. In: Pena M, Bacallao J, organizadores. La obesidad en la pobreza - un nuevo reto para la salud pública. Washington DC: Organización Panamericana de la Salud; 2000. p. 13-25.
16. Zaluar A. A máquina e a revolta: as organizações populares e o significado da pobreza. São Paulo: Brasiliense; 1985.

17. Gross D. The great sisal scheme. Natural History 1971; 3:55-65.

18. Silva DO. O fiel da balança na história do corpo obeso em mulheres de baixa renda [Dissertação de Mestrado]. Rio de Janeiro: Escola Nacional de Saúde Pública, Fundação Oswaldo Cruz; 1997.

19. Tonial SR. Desnutrição e obesidade: faces da desigualdade social no acesso aos alimentos e nas representações do corpo [Tese de Doutorado]. Rio de Janeiro: Instituto Fernandes Figueira, Fundação Oswaldo Cruz; 2001.

20. Unidade de Cuidados Primários de Saúde Dr. Albert Sabin. Estudo gerencial da UACPS Dr. Albert Sabin. Rio de Janeiro: Secretaria Municipal de Saúde do Rio de Janeiro; 2001.

21. Minayo MCS. Pesquisa social: teoria, método e criatividade. Petrópolis: Editora Vozes; 1988.

22. Lévis-Strauss C. Introdução à obra de Marcel Mauss. In: Mauss M. Sociologia e antropologia. São Paulo: Edusp; 1974. p. 1-36.

23. Sen AK. Desigualdade reexaminada. Rio de Janeiro: Record; 2001.

24. Townsend P. The international analysis of poverty. London: Harvester Wheatsheaf; 1993.

25. Rocha S. Caracterização da pobreza no Brasil. In: Instituto de Pesquisa Econômica Aplicada, organizador. O Brasil no fim do século: desafios e propostas para ação governamental. Rio de Janeiro: Instituto de Pesquisa Econômica Aplicada; 1994. p. 37-43.

26. Fischler C. Obeso benigno, obeso maligno. In: Sant'Anna DB, organizador. Políticas do corpo: elementos para uma história das práticas corporais. São Paulo: Estação Liberdade; 1989. p. 69-80.

27. Orbach S. Sobre a comida - reaprenda a comer e mude sua vida. Rio de Janeiro: Record; 2003.

28. Rocha S, Tolosa H. Metropolização da pobreza: uma análise núcleo-periferia. In: Instituto de Pesquisa Econômica Aplicada, organizador. Perspectivas da economia brasileira. Rio de Janeiro: Instituto de Pesquisa Econômica Aplicada; 1993. p. 527-39.

29. Lavinas L. Empregabilidade no Brasil: inflexões de gênero e diferenciais femininos. Rio de Janeiro: Instituto de Pesquisa Econômica Aplicada; 2001. (Texto para Discussão n. 826).

30. Buss PM. Promoção da saúde e qualidade de vida. Ciênc Saúde Coletiva 2000; 5:163-77.

Recebido em 16/Nov/2004

Versão final reapresentada em 10/Mar/2005

Aprovado em 20/Mai/2005 